\title{
ARES I-X LAUNCH VEHICLE MODAL TEST OVERVIEW
}

\author{
R. D. Buehrle, J. D. Templeton, M. C. Reaves, L. G. Horta and J. L. Gaspar \\ NASA Langley Research Center \\ Mail Stop 424, Hampton, VA 23681 \\ P. A. Bartolotta \\ NASA Glenn Research Center \\ R. A. Parks and D. R. Lazor \\ NASA Marshall Space Flight Center
}

\begin{abstract}
The first test flight of NASA's Ares I crew launch vehicle, called Ares I-X, was launched on October 28, 2009. Ares I-X used a 4-segment reusable solid rocket booster from the Space Shuttle heritage with mass simulators for the $5^{\text {th }}$ segment, upper stage, crew module and launch abort system. Flight test data provided important information on ascent loads, vehicle control, separation, and first stage reentry dynamics. As part of hardware verification, a series of modal tests were designed to verify the dynamic finite element model (FEM) used in loads assessments and flight control evaluations. Based on flight control system studies, the critical modes were the first three free-free bending mode pairs. Since a test of the free-free vehicle was not practical within project constraints, modal tests for several configurations in the nominal integration flow were defined to calibrate the FEM. A traceability study by Aerospace Corporation was used to identify the critical modes for the tested configurations. Test configurations included two partial stacks and the full Ares I-X launch vehicle on the Mobile Launcher Platform. This paper describes the requirements flow down, pre-test analysis, constraints and overall test planning for the Ares I-X modal tests. Companion papers will provide additional details on the test execution and model calibration process.
\end{abstract}

\section{INTRODUCTION}

The 327 foot 1.8 million-pound Ares I-X launch vehicle ${ }^{1}$ is shown in Figure 1. Ares I-X consists of a 4segment reusable solid rocket motor from the Space Shuttle heritage with mass simulators for the $5^{\text {th }}$ segment, upper stage, crew module (CM) and launch abort system (LAS). NASA Langley Research Center (LaRC) built the CM/LAS simulator. NASA Glenn Research Center (GRC) built the upper stage simulator and ATK built the first stage. Integration of the vehicle was performed in the Vehicle Assembly Building at NASA's Kennedy Space Center (KSC). Ares I-X was successfully launched on October 28, 2009 and served as the first flight test for NASA's Ares I crew launch vehicle. Flight test data provided important information on ascent loads, vehicle control, separation, and first stage reentry dynamics.

As part of hardware verification for Ares I-X, a series of modal tests were designed to verify the dynamic finite element model (FEM) used in loads assessments and flight control evaluations. The first three free-free bending mode pairs were defined as the target modes for the modal test based on the flight control requirements. Since a test of the free-free vehicle configuration was not practical within the projects constraints, calibration of the FEM was done using modal test data for several configurations in the nominal KSC integration flow.

This paper defines the test configurations and requirements based on a flow down from the defined freefree bending modes of interest. FEM pre-test analysis is used to define the response transducer and shaker locations for each test configuration. Project constraints on instrumentation numbers and vehicle accessibility are also discussed as part of the transducer/shaker placement studies. The project schedule required that the team conduct the tests and verify the sufficiency of the data in a three to four day test window for each configuration. Companion papers ${ }^{2-5}$ provide further detail on the test execution and results. 


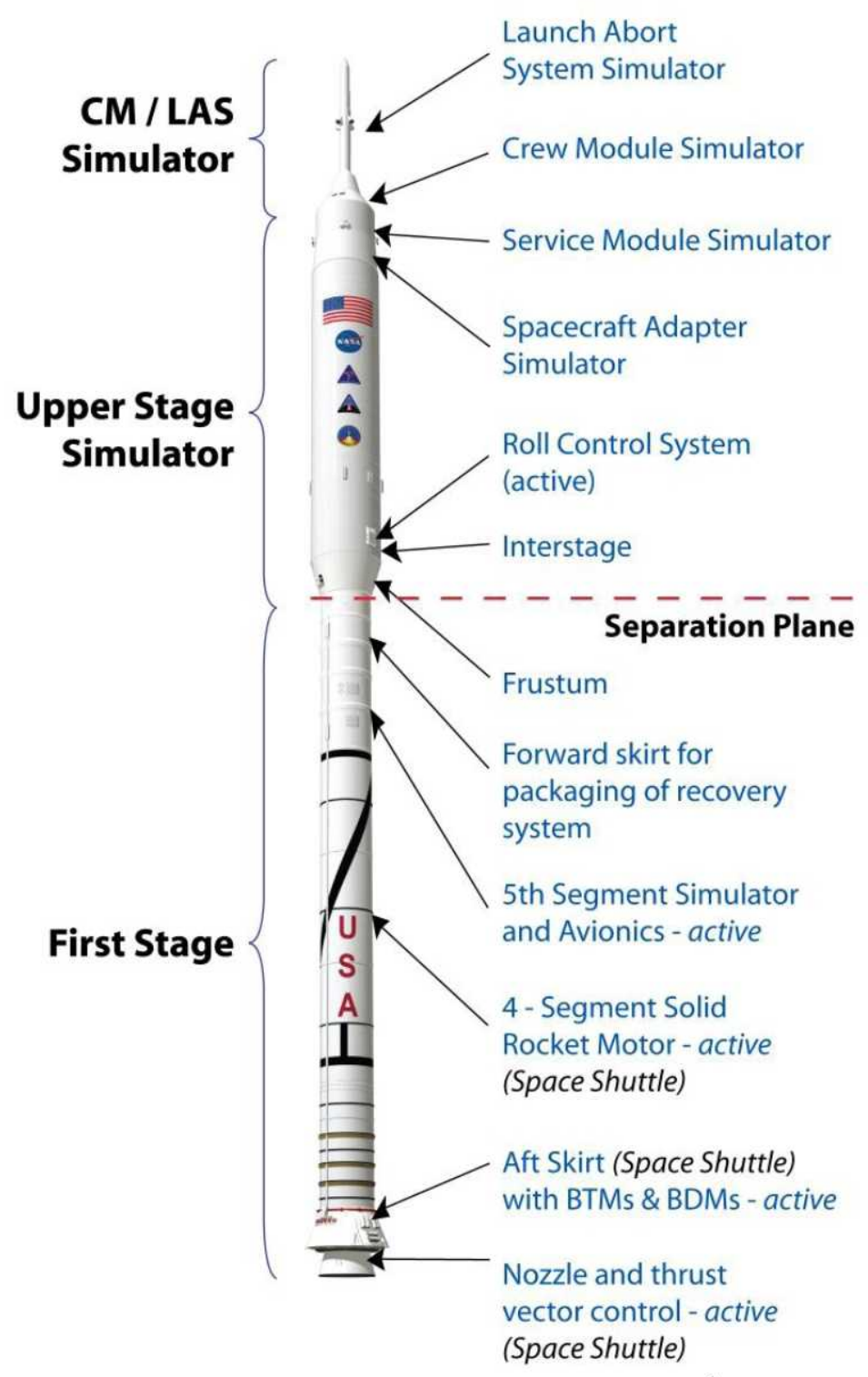

Figure 1. Ares I-X Flight Test Vehicle ${ }^{1}$

\section{TEST CONFIGURATIONS}

The modal verification for Ares I-X focused on new hardware systems. The Shuttle heritage hardware on the first stage (see Figure 1) had FEMs that had been test verified. The $5^{\text {th }}$ segment simulator, upper stage and CM/LAS were new hardware. The FEMs for the new hardware had not been test verified.

The target free-free bending modes are shown in Figure 2. Due to vehicle symmetry, a companion set of modes occur in the orthogonal bending plane (not shown). These orthogonal "mode pairs" occur at nearly the same frequency. Based on visual inspection of the first three free-free bending mode shapes shown in Figure 2, the center section of the vehicle displays significant deformations for the $1^{\text {st }}$ and $2^{\text {nd }}$ bending modes. The CM/LAS deformations dominate the $3^{\text {rd }}$ bending mode. These areas of the vehicle are also new hardware without previous test verification. Therefore, the Stack 1 and Stack 5 subassemblies shown in Figure 3 were selected for subassembly modal tests. These tests were meant to provide an early assessment of FEM accuracy for the subassemblies. The test configurations were available in the nominal vehicle integration flow and no special provisions were made for the subassembly boundary conditions or mass loading of the unsupported edges. This was due to project cost and schedule constraints. The test team recognized the risk that the unknown boundary 
conditions posed to the partial stack tests. In an effort to account for boundary interface compliance ${ }^{4}$, additional measurements were defined across the boundaries.

The final test in the verification process was for the full flight test vehicle (FTV) on the Mobile Launcher Platform (MLP) as illustrated in Figure 4. The hardware suppliers provided the corresponding FEM for the assemblies. This included a CM/LAS model from NASA LaRC, an upper stage model from NASA GRC, a first stage model from ATK, and an MLP model from NASA KSC. These models were integrated at LaRC and initial model checkouts were performed. The models were then released for loads and control system evaluations. The modal test provided a needed check on the fidelity of the integrated model.

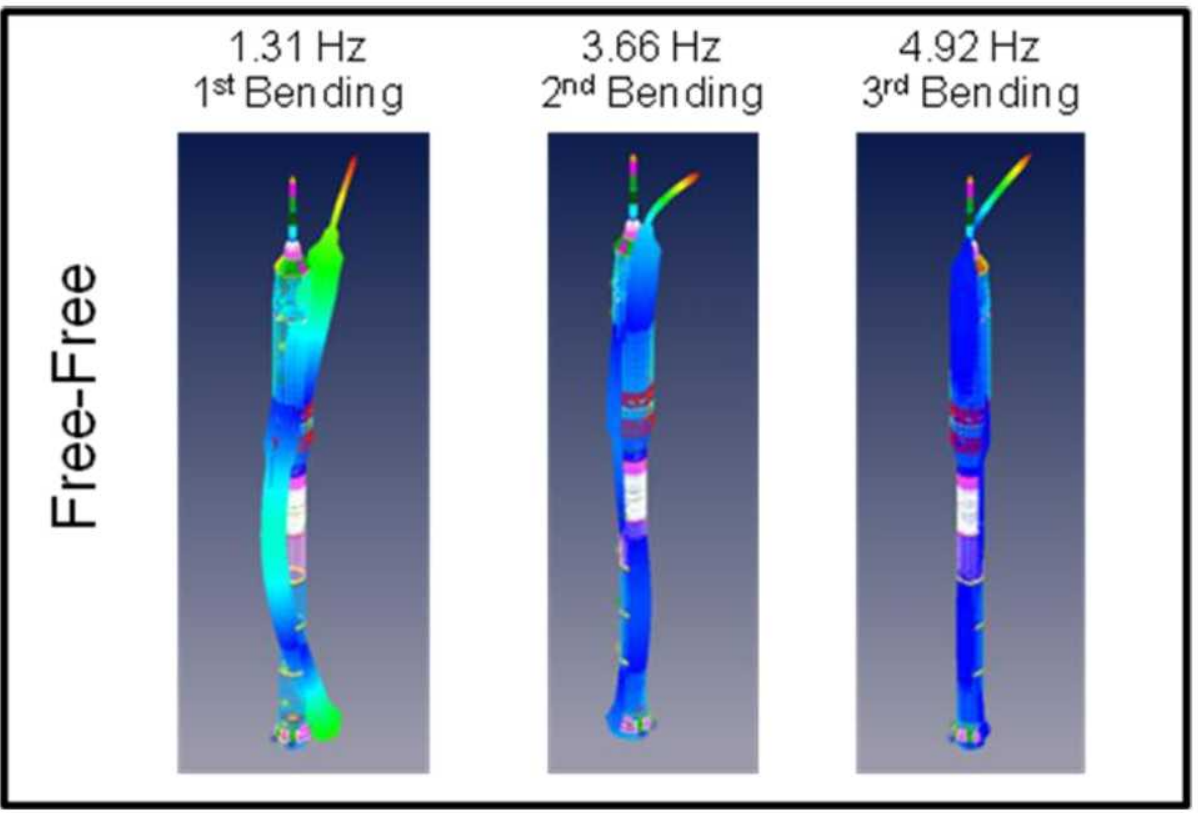

Figure 2. Free-free bending modes of interest.

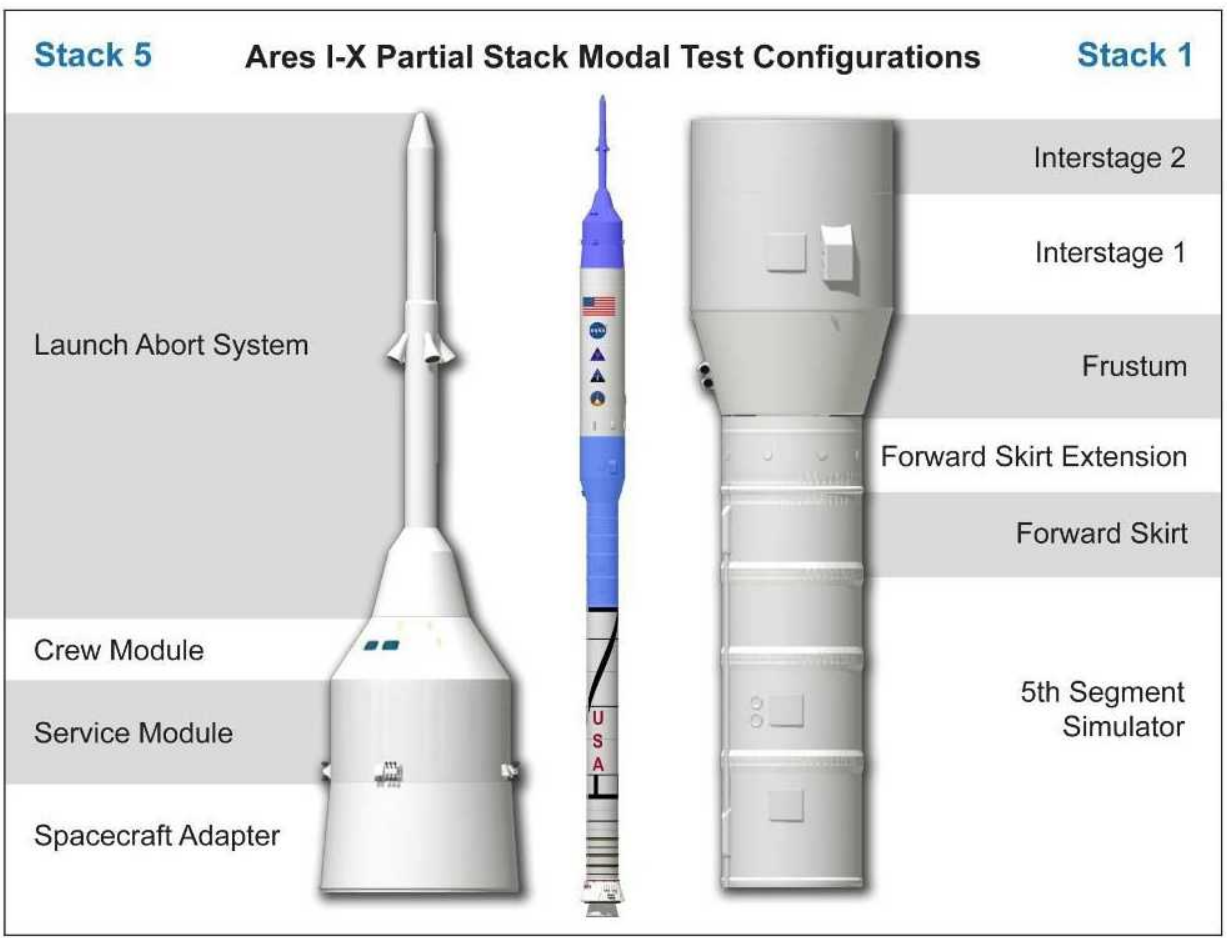

Figure 3. Ares I-X Subassembly Modal Test Configurations ${ }^{6}$ 


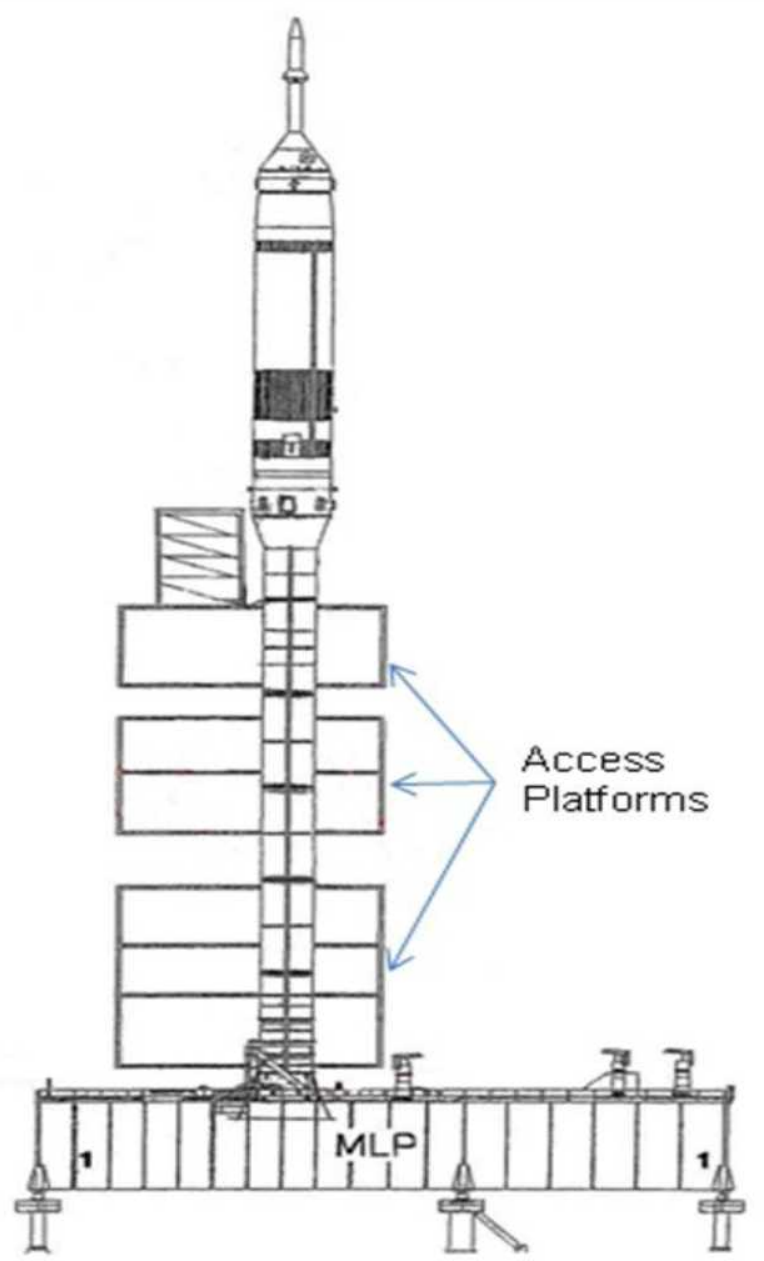

Figure 4. Schematic of Ares I-X Flight Test Vehicle on the Mobile Launcher Platform.

\section{TEST REQUIREMENTS}

The modal tests were designed to minimize impact to the project integration flow and schedule. As such, the project emphasized minimal instrumentation to characterize the bending modes but did not define hard limits on test/analysis orthogonality metrics. The metrics for this test series were to verify that the differences found between test and analysis were within the variances assumed for flight control Monte-Carlo studies. The assumed Monte-Carlo variances were: $10 \%$ for $1^{\text {st }}$ bending mode frequency and $20 \%$ for higher modes; node locations within $+/$ - 100 inches; and deformations within $20 \%$ of nominal for the $1^{\text {st }}$ bending mode pair and $50 \%$ for higher modes. While these requirements could not be verified on the free-free configuration, the calibration of the model for comparable modes for the FTV on the MLP was deemed sufficient to verify the FEM. The predictions of the free-free modes were then assumed to have similar test/analysis variances as determined for the FTV on MLP configuration.

Figure 5 shows the flow down from the free-free target modes of interest to the comparable modes for the FTV on the MLP. There is a strong similarity between the first three free-free bending modes and the $2^{\text {nd }}$ through $4^{\text {th }}$ bending modes on the MLP. Therefore, the target modes for the integrated FTV on the MLP were the first four bending mode pairs. The $1^{\text {st }}$ mode pair on the MLP was not important for controls but was critical for transportation to the launch pad. 


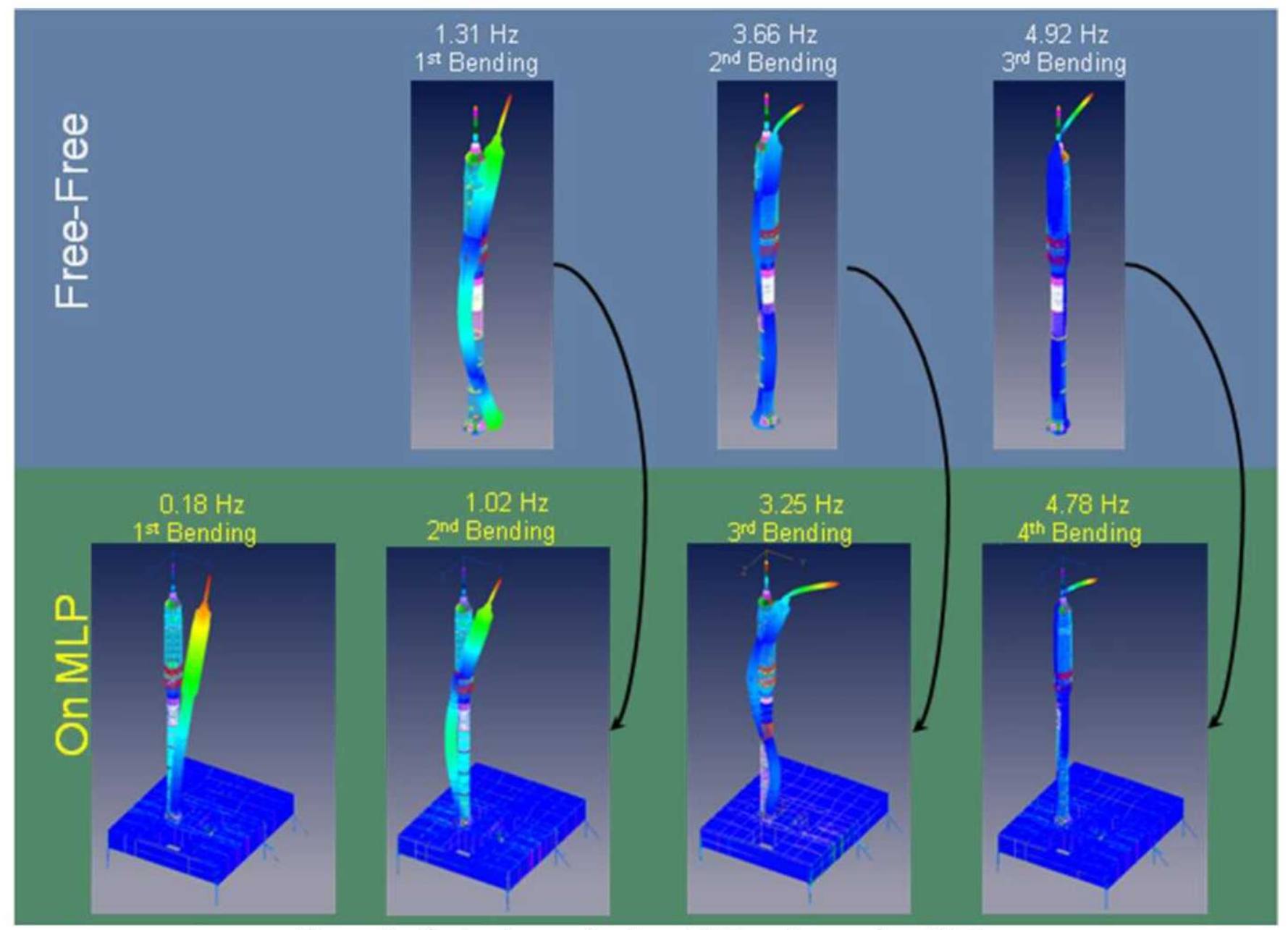

Figure 5. Mode shapes for Ares I-X Free-free and on MLP.

Initially, target modes for the Stack 1 and Stack 5 subsystems were focused on identifying the first two or three bending mode pairs for each configuration. These target bending modes will be further defined in the PreTest Analysis section. A more detailed traceability study ${ }^{2}$ was conducted based on subsystem coupling and energy distribution to establish the subsystem target modes that were important to the FTV free-free modes of interest. The defined modes from the traceability study were covered within the frequency/mode range identified in the following Pre-Test Analysis section.

\section{PRE-TEST ANALYSIS}

The project emphasized minimal instrumentation to characterize the bending modes but did not define hard limits on test/analysis orthogonality metrics. The goal established prior to pre-test analysis was for approximately 20 sensor locations with biaxial accelerometers for capturing the bending modes. As will be shown, the sensor count was extended to approximately 40 locations in an effort to improve the crossorthogonality metrics. Sensor and shaker placement was performed using the pre-test FEM. The effective independence ${ }^{7}$ technique along with engineering judgment was used in the sensor placement. There were additional physical constraints of the test setup that would limit the shaker placement to available platform elevations. For example, the flight test vehicle shown in Figure 4 had no external access for shaker or accelerometer mounting above the first stage. All instrumentation would be mounted internally for the upper stage and CM/LAS.

Pre-test analysis was also used to simulate the test. The simulated test data was used to evaluate the required force and expected acceleration amplitudes. This was used for selection of the shakers and accelerometers, and test planning. 
The Stack 5 configuration (see Figure 6) consists of the spacecraft adapter (SA), service module (SM), crew module (CM) and launch abort system (LAS) mounted on the super-segment assembly stand (SSAS) and heavy weight upper stage simulator (USS) transportation cart. The cart had the wheels removed and was shimmed level on the floor of VAB High Bay 4. The SSAS and heavy weight cart models were added into the FEM. Springs were placed at the shim locations to account for the boundary compliance for the pre-test analysis. A nominal boundary spring stiffness of $6 \times 10^{7} \mathrm{lb} / \mathrm{in}$ was used for the pre-test analysis. The pre-test modes are listed in Table 1 and shown in Figure 7 . The LAS bending modes $(1,2,5$, and 6 ) were found to be insensitive to the boundary stiffness. Instrumentation was placed at the boundary to assess the true interface compliance.

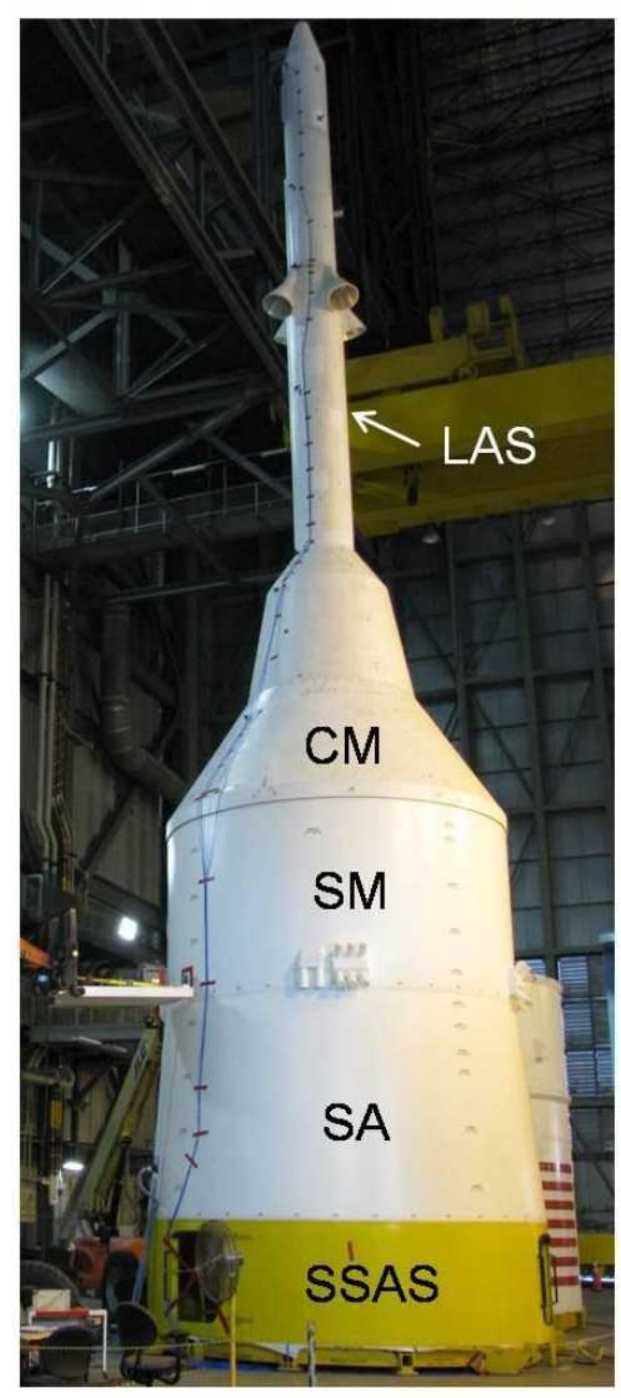

Figure 6. Stack 5 test configuration.

\begin{tabular}{|c|c|c|}
\hline \multicolumn{3}{|c|}{ Table 1 Pre-Test Modes for Stack 5 Test } \\
\hline Mode No. & $\begin{array}{c}\text { Frequency } \\
\text { (Hz) }\end{array}$ & Mode Description \\
\hline 1 & 4.60 & LAS 1st Bending (X-Y Plane) \\
\hline 2 & 4.67 & LAS 1st Bending (X-Z Plane) \\
\hline 3 & 12.2 & System 2nd Bending (X-Y Plane) \\
\hline 4 & 14.7 & System 2nd Bending (X-Z Plane) \\
\hline 5 & 26.1 & LAS 2nd Bending (X-Y Plane) \\
\hline 6 & 26.2 & LAS 2nd Bending (X-Z Plane) \\
\hline
\end{tabular}

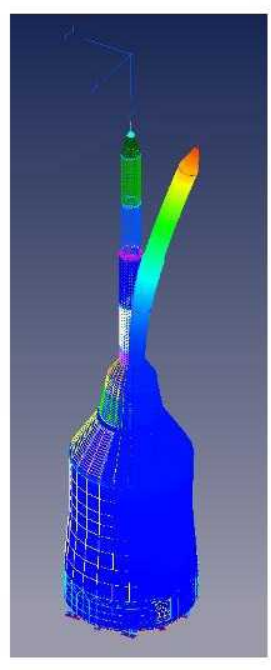

$4.60 \mathrm{~Hz}, 4.67 \mathrm{~Hz}$

Mode $1 X-Z$

Mode $2 X-Y$

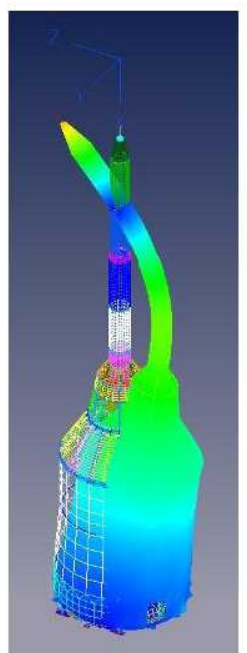

$12.2 \mathrm{~Hz}, 14.7 \mathrm{~Hz}$

Mode $3 X-Z$

Mode $4 X-Y$

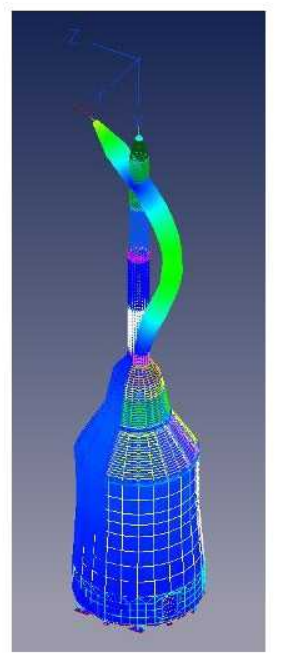

$26.1 \mathrm{~Hz}, 26.2 \mathrm{~Hz}$

Mode $5 X-Z$

Mode $6 \mathrm{X}-\mathrm{Y}$

Figure 7. Stack 5 Predicted Mode Shapes.

Based on the target modes in Table 1, sensor placement was performed using effective independence ${ }^{7}$ but adjusted using engineering judgment. The resulting measurement locations are shown on Figure 8 . There are 20 biaxial and 10 triaxial sets of accelerometers defined for this test. The 45,042 degree of freedom (DOF) FEM was reduced to a 70 DOF test model. The corresponding cross-orthogonality between the reduced model (corresponding to the test instrumentation set) and the full model is used to assess the adequacy of the test instrumentation set as shown in Figure 9. Diagonal terms for the cross-orthogonality matrix are $\geq 0.95$ and the offdiagonal terms are generally $<0.1$. However, the off-diagonal terms for mode pair 5,6 were 0.3 . This was deemed acceptable for this minimal instrumentation set. Figure 8 also shows the two shaker locations that were 
determined to be the optimal locations within the elevation constraints imposed by the project. The elevation constraint was due to the fact that the test hardware was resting on the floor without surrounding infrastructure. Heavy lift equipment was required for shaker positioning.

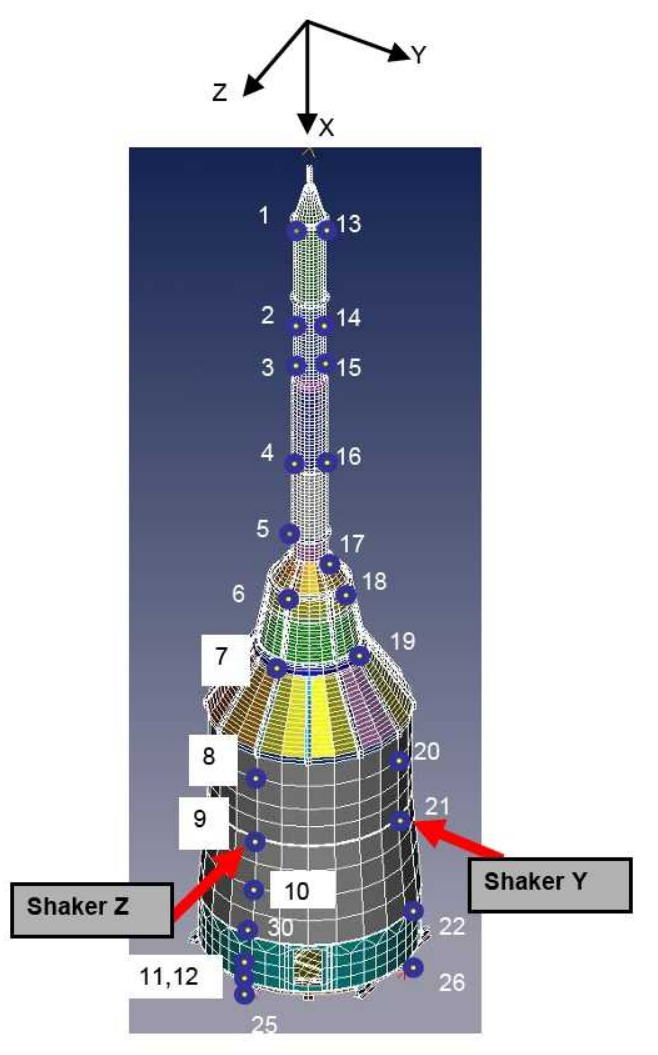

Figure 8. Stack 5 sensor/shaker locations.

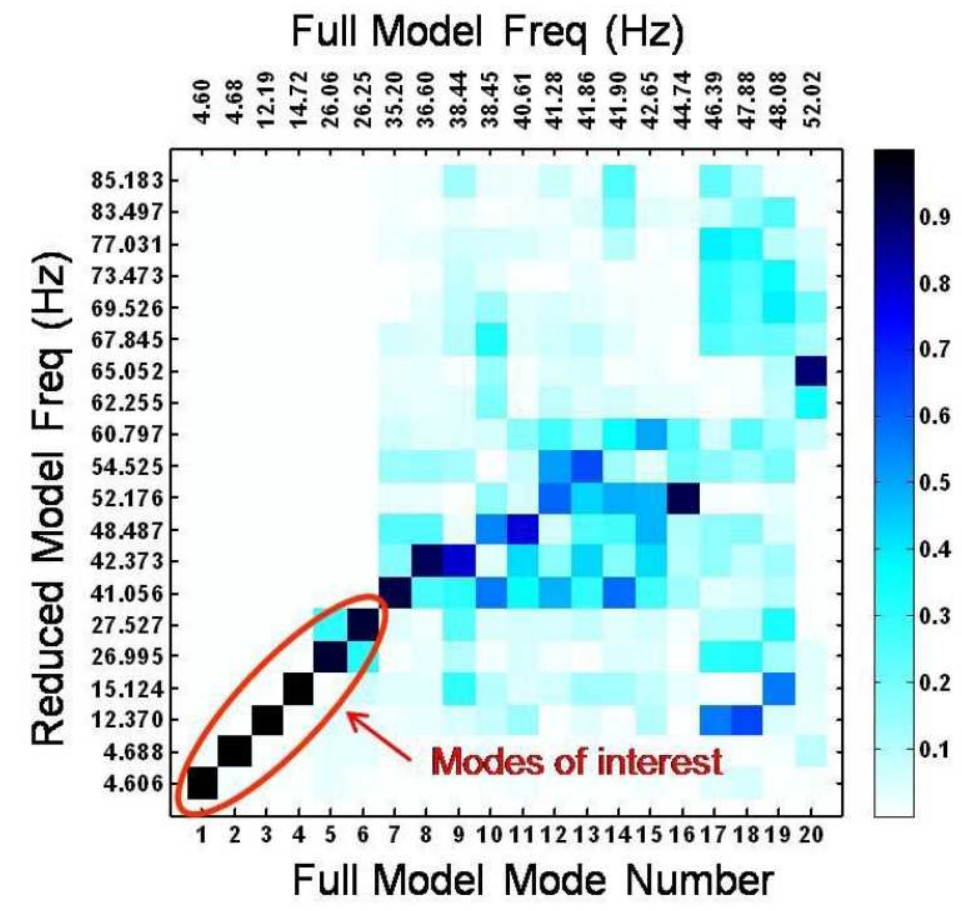

Figure 9. Stack 5 cross-orthogonality.

\section{STACK 1 PRE-TEST ANALYSIS}

The Stack 1 configuration consists of the $5^{\text {th }}$ segment simulator, forward skirt, forward skirt extension, frustum, interstage-1, and interstage-2 as shown in Figure 3. Again, the test segment was shimmed at 12 locations to level the structure. The FEM incorporated springs at the shim locations to account for interface compliance. A baseline boundary stiffness value of $1 \times 10^{7} \mathrm{lb} /$ in was used. Instrumentation at the boundary was planned to aide in assessing the true interface compliance ${ }^{4}$. Table 2 shows the FEM pretest predictions with the target modes highlighted. The corresponding mode shapes are shown in Figure 10.

Based on these target modes, the effective independence technique was used to determine the sensor and shaker locations. The resulting measurement locations are shown on Figure 11. The 59,574 DOF FEM was reduced to an $88 \mathrm{DOF}$ test model. The cross-orthogonality between the reduced model (corresponding to the test instrumentation set) and the full model are shown in Figure 12. The correlation for the first six modes is consistent with goals of having $>0.9$ on the diagonal and $<0.1$ on the off-diagonal terms. This implies that the test instrumentation set is suitable for capturing the first six modes based on the cross-orthogonality metric. The modes with bending $(1,2,6,7$, and 8$)$ are of primary interest for traceability to the flight test vehicle configuration. Although it is anticipated that modes 7 and 8 will not meet cross-orthogonality goals, qualitative comparisons of mode shapes and frequency response function data will be used to evaluate these modes. This was due to the use of minimal instrumentation and a late change in the FEM after instrumentation installation had begun. Adequate time prior to testing was not available to reassess the instrumentation placement due to the FEM changes. The free-edge at the top of interstage-2 also resulted in significant shell motion (see Figure 10) making it difficult to obtain adequate spatial resolution with the limited instrumentation set. 
Table 2 Pre-Test Modes for Stack 1 Test

\begin{tabular}{|c|c|c|}
\hline Mode No. & $\begin{array}{c}\text { Frequency } \\
(\mathbf{H z})\end{array}$ & Mode Description \\
\hline 1 & 4.07 & Stack 1st Bending \\
\hline 2 & 4.14 & Stack 1st Bending \\
\hline 3 & 16.2 & Interstage 2N shell mode \\
\hline 4 & 16.7 & Interstage 2N shell mode \\
\hline 5 & 17.3 & Torsion \\
\hline 6 & 22.0 & $\begin{array}{c}\text { Interstage 3N shell mode, } \\
\text { coupled with stack 2 }\end{array}$ \\
\hline 7 & 22.7 & $\begin{array}{c}\text { Interstage 3N shell mode, } \\
\text { coupled with stack 2 }\end{array}$ \\
\hline 8 & 23.3 & $\begin{array}{c}\text { Interstage 3N shell mode, } \\
\text { coupled with stack 2 }\end{array}$ \\
\hline
\end{tabular}

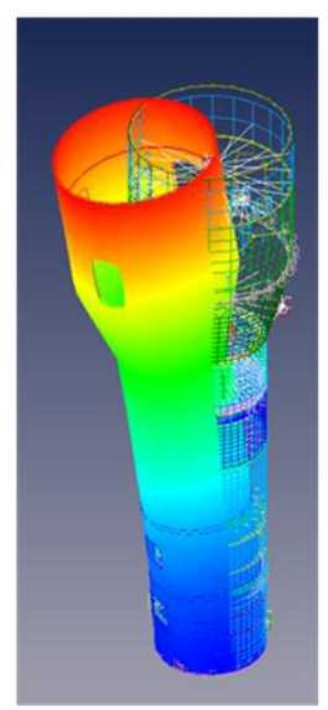

Mode 1

$4.07 \mathrm{~Hz}$

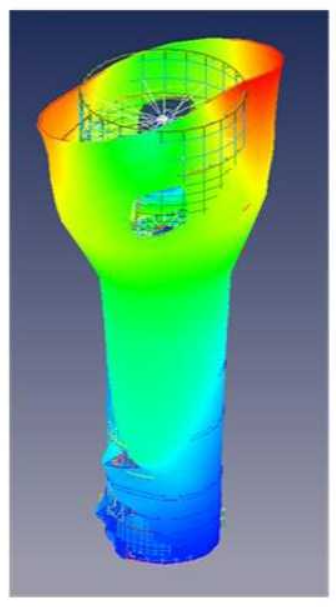

Mode 5

$17.3 \mathrm{~Hz}$

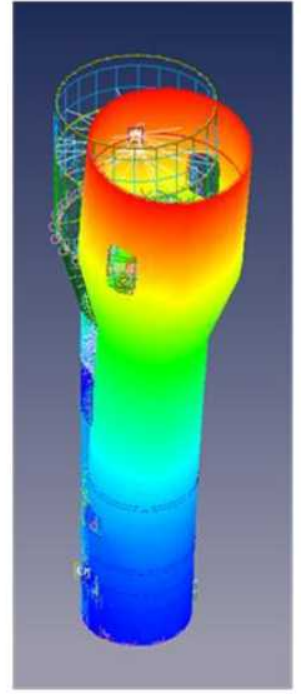

Mode 2

$4.14 \mathrm{~Hz}$

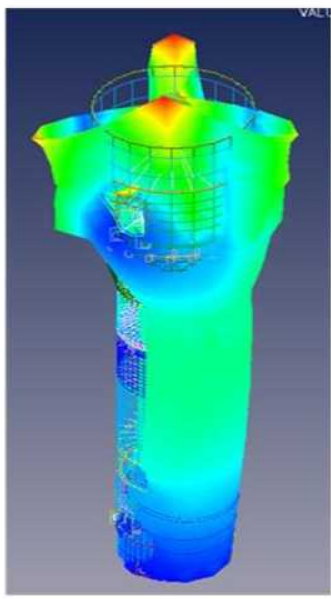

Mode 6

$22.04 \mathrm{~Hz}$

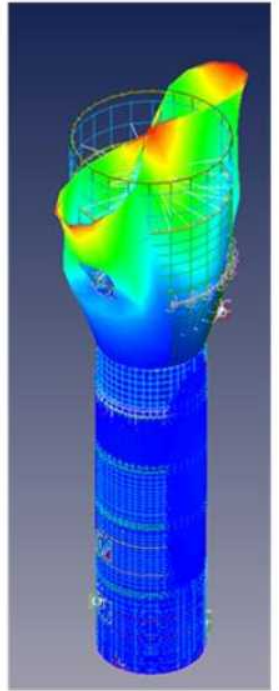

Mode 3

$16.17 \mathrm{~Hz}$

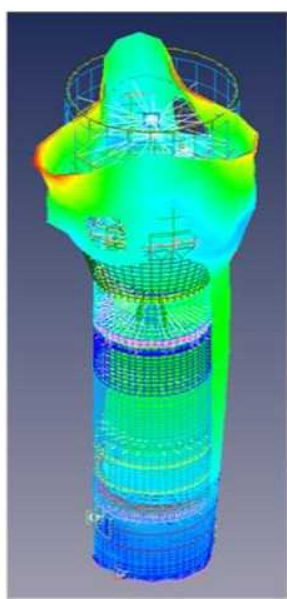

Mode 7

$22.71 \mathrm{~Hz}$

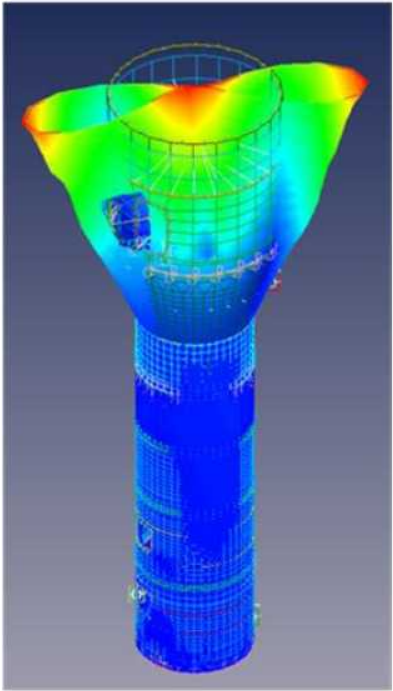

Mode 4

$16.73 \mathrm{~Hz}$

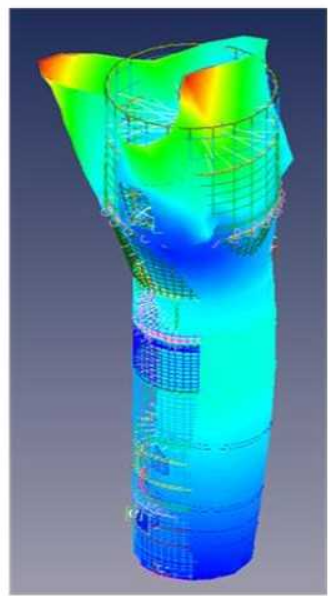

Mode 8

$23.26 \mathrm{~Hz}$

Figure 10. Stack 1 Predicted Mode Shapes. 


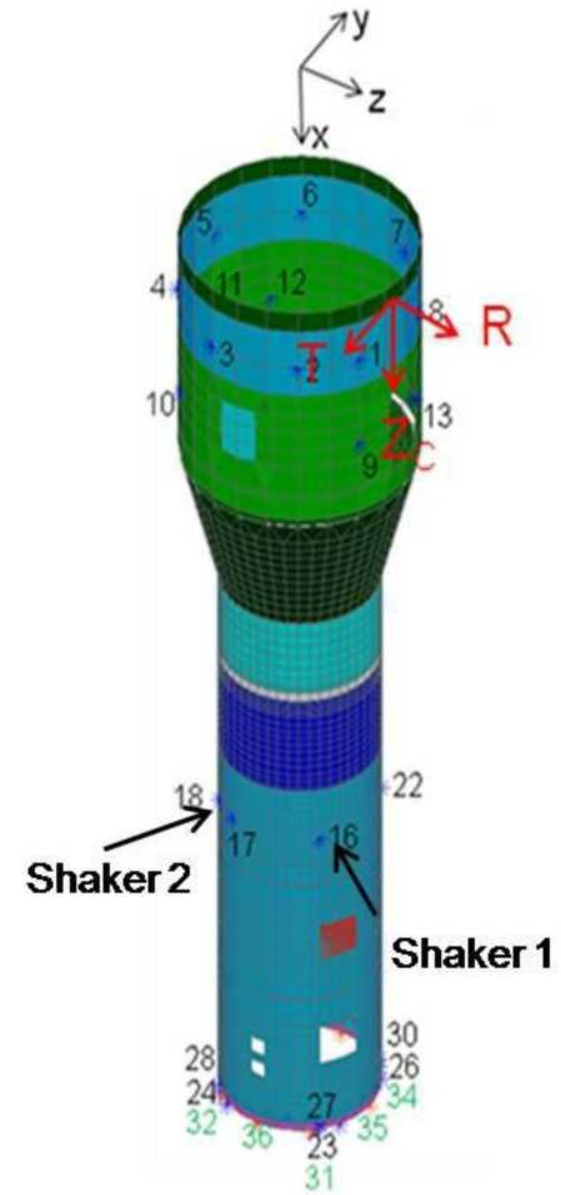

Figure 11. Stack 1 sensor/shaker locations.

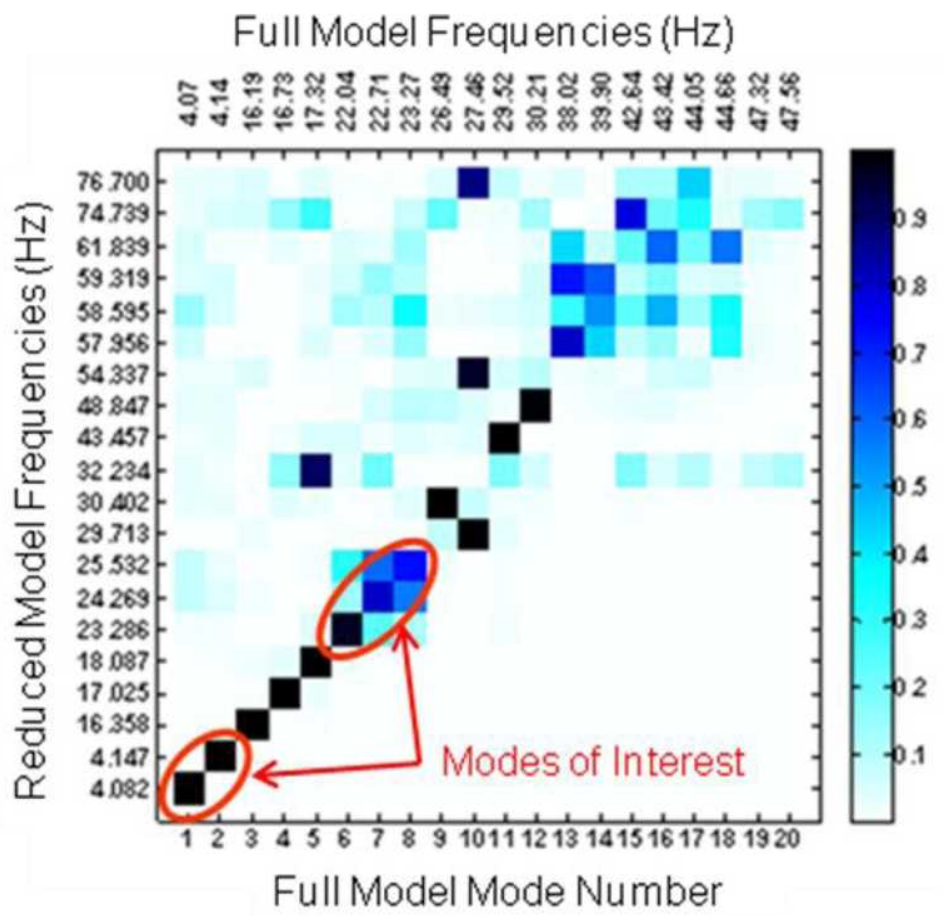

Figure 12. Stack 1 cross-orthogonality.

\section{FLIGHT TEST VEHICLE PRE-TEST ANALYSIS}

Table 3 lists the FEM predictions of the first 14 modes with the target modes highlighted. The corresponding target mode shapes for the X-Y Plane were previously shown in Figure 5. Based on these target bending modes, a line of sensors that could be accessed from existing facility platforms and internal ladders was selected. Cross-orthogonality was then used to evaluate the sensor set and make adjustments. In addition, triaxial accelerometers (numbers 24-26) were located at the three control sensor locations. The resulting measurement locations are shown on Figure 13. This includes a combination of axial, biaxial and triaxial accelerometers at 34 locations on the vehicle and MLP. Also, shown are the four shaker locations that were determined to be the optimal locations with platform access for mounting. The cross-orthogonality between the reduced model (corresponding to the test instrumentation set) and the full model is used to assess the adequacy of the test instrumentation set as shown in Figure 14. It is important to note that the 346,860 degree of freedom (DOF) finite element model has been reduced to an $82 \mathrm{DOF}$ test model. As a result, system modes at $4.66 \mathrm{~Hz}$ and $4.92 \mathrm{~Hz}$ are not predicted in the reduced order model resulting in an offset from the diagonal in the crossorthogonality plot. The diagonal terms for the target modes are $>.85$ and the off-diagonal terms generally less than 0.1 . The torsion mode at $3.58 \mathrm{~Hz}$ and system mode at $4.66 \mathrm{~Hz}$ are the source of most of the exceptions to the off-diagonal terms. This was deemed acceptable with the project constraints on instrumentation. The measured data will need to be sieved to eliminate the torsion mode and modes with significant MLP participation to focus the correlation on the Ares I-X vehicle bending modes of interest. The MLP and $1^{\text {st }}$ stage (including aft skirt) are considered validated models based on Shuttle test heritage and were therefore not a focus of this test. Six additional sensor locations were added to the pre-test analysis set to better define the vehicle interface with the MLP and to separate out the torsion mode. This included tangential accelerometers 180 degrees from locations 4,12 , and 21 to help resolve the $3^{\text {rd }}$ bending and torsion modes at approximately $3.5 \mathrm{~Hz}$. 
Table 3 Flight Test Vehicle on MLP Predicted Modes

\begin{tabular}{|c|c|c|}
\hline Mode No. & $\begin{array}{c}\text { Frequency } \\
(\mathrm{Hz})\end{array}$ & Mode Description \\
\hline 1 & 0.176 & $1^{\text {st }}$ Bending Mode of Ares1-X (X-Y Plane) \\
\hline 2 & 0.216 & $1^{\text {st }}$ Bending Mode of Ares $1-X(X-Z$ Plane $)$ \\
\hline 3 & 1.02 & $2^{\text {nd }}$ Bending Mode of Ares1-X (X-Y Plane) \\
\hline 4 & 1.17 & $2^{\text {nd }}$ Bending Mode of Ares1-X (X-Z Plane) \\
\hline 5 & 1.87 & Ares1-X / MLP System lateral mode \\
\hline 6 & 2.66 & Ares1-X / MLP System lateral mode \\
\hline 7 & 3.25 & $3^{\text {rd }}$ Bending Mode of Ares1-X (X-Y Plane) \\
\hline 8 & 3.49 & Ares1-X / MLP System mode \\
\hline 9 & 3.50 & $3^{\text {rd }}$ Bending Mode of Ares1-X (X-Z Plane) \\
\hline 10 & 3.58 & Ares1-X Torsion \\
\hline 11 & 4.22 & Ares1-X / MLP System mode \\
\hline 12 & 4.66 & Ares1-X / MLP System mode \\
\hline 13 & 4.78 & $4^{\text {th }}$ Bending Mode of Ares1-X (X-Y Plane) \\
\hline 14 & 4.84 & 4th Bending Mode of Ares1-X (X-Z Plane) \\
\hline
\end{tabular}

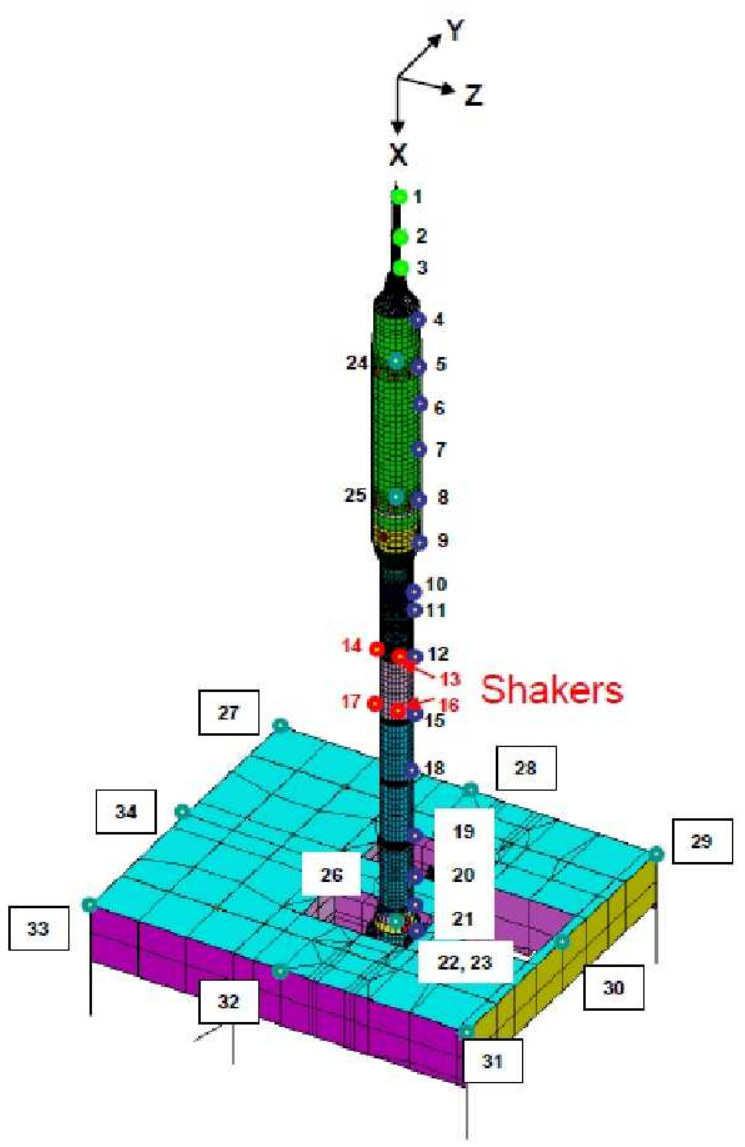

Figure 13. FTV on MLP sensor/shaker locations.

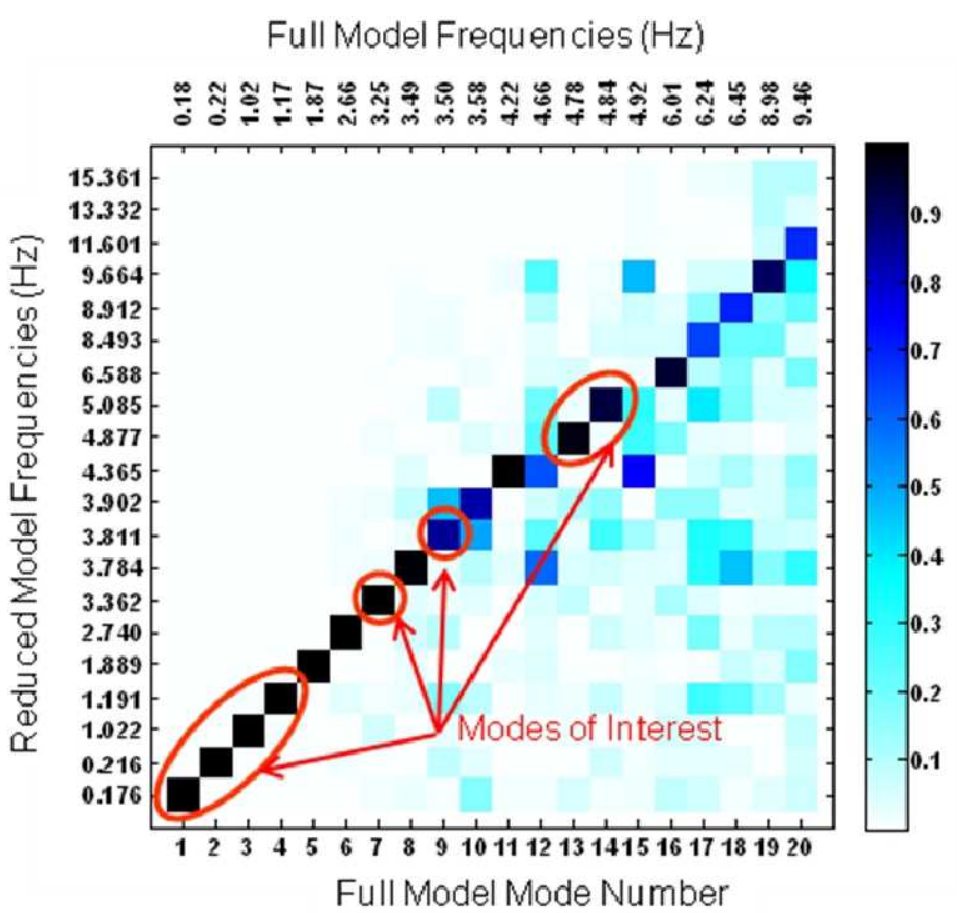

Figure 14. FTV on MLP cross-orthogonality. 


\section{TEST PLANS}

The tests were designed to measure the target modes identified in the test requirements and pre-test analysis sections. The primary datasets for modal parameter estimation would be frequency response functions for multi-input random or burst random excitation at several force levels. Sine sweeps using a single shaker were planned to check for linearity of selected modes with respect to force level. Due to constraints on shaker placement, impact testing was planned to aide in the resolution of target and/or local modes. The partial stack tests were scheduled for two test days with a data evaluation day between them. The flight test vehicle (FTV) modal test was scheduled for three test days with a data evaluation day after the first test day. The data evaluation day was for comparison of initial test results with pre-test analyses and to make any necessary adjustments to the test plans to ensure that all target modes were identified. A companion paper by Templeton ${ }^{3}$ provides details of the test setup and test results.

\section{SUMMARY}

Modal tests for two subsystems in the nominal integration flow and a test of the fully integrated flight test vehicle on the Mobile Launcher Platform were defined for calibration of the Ares I-X vehicle model. Schedule and cost constraints led to the decision to test the subsystems with the test articles resting on shims. The target modes for the FTV modal test were defined based on the first three free-free bending mode pairs that were critical for control system evaluations. Target modes for the partial stack tests focused on modes with significant bending motion that would trace back to the vehicle bending modes of interest. Based on the target modes, pretest analysis was used to define the sensor and shaker locations using effective independence. Constraints on the quantity and physical accessibility also influenced the sensor and shaker placement. Project schedules dictated that each test be conducted over a three to four day period including initial test/analysis assessments. The three tests were completed on schedule from May through August $2009^{8-10}$. Companion papers ${ }^{3-5}$ provide additional detail on the test execution and model calibration process.

\section{ACKNOWLEDGEMENTS}

Thanks go to Winifred Feldhaus of NASA Langley Research Center for her assistance with finite element model development. The test execution phase at Kennedy Space Center (KSC) could not have been done without the support of many individuals. Special thanks go to the KSC instrumentation team led by Frank Walker, which routed approximately 28000 feet of cable for the Flight Test Vehicle alone. Logistics and test hardware integration went smoothly due to the dedicated KSC crew that included Russ Brucker, Trip Healey, Stephanie Heffernan, Teresa Kinney, Todd Reeves, Kara Schmitt, Mark Tillett, and Jim Wiltse. Lastly, thanks to our independent verification team of Jeff Lollock, Ryan Tuttle, and Joshua Hwung from Aerospace Corporation.

\section{REFERENCES}

1. NASA Fact Sheet, Constellation Program: Ares I-X Flight Test Vehicle, FS-2009-03-007-JSC, 2009. http://www.nasa.gov/pdf/354470main aresIX fs may09.pdf

2. Tuttle, R., Lollock, J. A., and Hwung, J.S.; Identifying Goals for Ares I-X Modal Testing, Proceedings of IMAC XXVIII, Jacksonville, Florida, February 1-4, 2010.

3. Templeton, J. D., Buehrle, R. D., Parks, R. A., Lazor, D. R., and Gaspar, J. L.; Ares I-X Launch Vehicle Modal Test Measurements and Data Quality Assessments, Proceedings of IMAC XXVIII, Jacksonville, Florida, February $1-4,2010$.

4. Tuttle, R., and Lollock, J. A.; Modal Test Data Adjustment for Interface Compliance, Proceedings of IMAC XXVIII, Jacksonville, Florida, February 1-4, 2010.

5. Horta, L. G., Reaves, M. C., Buehrle, R. D., Templeton, J. D., Lazor, D. R., Gaspar, J. L., Parks, R. A.., and Bartolotta, P. A..; Finite Element Model Calibration Approach for Ares I-X, Proceedings of IMAC XXVIII, Jacksonville, Florida, February 1-4, 2010.

6. NASA, 2009. http://www.nasa.gov/images/content/351392main Moda \%20Stack Configs.jpg

7. Kammer, D. C.; Sensor Placement for On-Orbit Modal Identification and Correlation of Large Space Structures, Journal of Guidance, Volume 14, No. 2, March-April 1991. 
8. Buehrle, R. D., Templeton, J. D.; Bartolotta, P. A.; Reaves, M. C.; Horta, L. G.; Parks, R. A.; Lazor, D. R.; Gaspar, J. L.: Ares I-X Flight Test Vehicle Modal Test, NASA/TM-2010-216182, January 2010.

9. Buehrle, R. D., Templeton, J. D.; Bartolotta, P. A.; Reaves, M. C.; Horta, L. G.; Parks, R. A.; Lazor, D. R.; Gaspar, J. L.: Ares I-X Flight Test Vehicle: Stack 5 Modal Test NASA/TM-2010-216183, January 2010.

10. Buehrle, R. D., Templeton, J. D.; Bartolotta, P. A.; Reaves, M. C.; Horta, L. G.; Parks, R. A.; Lazor, D. R.; Gaspar, J. L.: Ares I-X Flight Test Vehicle: Stack 1 Modal Test, NASA/TM-2010-216210, March 2010. 